\title{
$\mathrm{BIM}$ 기반의 브레이스 접합부의 구조설계 인터페이스 모듈 개발
}

\author{
김 태 형 ${ }^{1)}$ - 신 태 송 ${ }^{2 *}$ \\ 1) 석사, 동명대학교, 건축공학과 ${ }^{2)}$ 교수, 동명대학교, 건축공학과
}

\section{Interface Module Developement of Structural Design for Brace Connections on based BIM}

\author{
Kim, Tae Hyeong ${ }^{1)} \quad$ Shin, Tae Songe* \\ 1) Graduate Student, Dept. of Architectural Engineering, Tongmyong University, Busan, 608-711, Korea \\ ${ }^{2)}$ Professor, Dept. of Architectural Engineering, Tongmyong University, Busan, 608-711, Korea
}

\begin{abstract}
This study is aimed at developing the structural design interface module for the brace connections in order to improve the efficiency of the interoperability between structural design and BIM modeling at the construction design phase of steel structures. For this purpose, structural design module is first established according to the algorithm built by structural design standards of domestic and foreign. Then, it is developed interface module which can export the data of 3D model obtained from the BIM design tools to structural design module and feed structural design results back to 3D BIM model. Finally, the efficiency and practicality of the developed interface module is verified by applying to a sample model
\end{abstract}

KEYWORDS : construction design phase, brace connections, BIM, interface module, algorithm

\section{1. 서 론}

\section{1 연구의 배경}

가새골조(Braced Frame)는 기둥과 보로 구성된 골조 내 에 가새부재를 설치하여 바람이나 지진과 같은 횡하중에 저 항할 수 있도록 강성 및 연성을 크게 하는 강구조의 대표적 인 구조시스템 중 하나이다 ${ }^{[1]}$. 이러한 가새 골조의 접합부는 일반적으로 거셋(gusset)을 통하여 보와 기둥사이의 경계면 에서 볼트나 용접에 의해 힘의 흐름을 전달하게 된다. 이때 접합부는 각 경계면사이에서 힘을 전달하는 방법은 여러 가

Note.-Discussion open until October 31, 2013. This manuscript for this paper was submitted for review and possible publication on December 28, 2012; revised February 14, 2013; approved on March 22, 2013. (c) KSSC 2013

\section{* Corresponding author}

Tel. +82-51-629-2461 Fax. +82-51-629-2429

E-mail: tsshin@tu.ac.kr
지 다양한 경우가 있을 수 있는데 접합부를 구성하고 있는 각 요소사이의 관계에 따라서 볼트와 용접부의 응력을 효과 적으로 설계하기 위한 절차가 필요하게 된다 ${ }^{[2]}$. 하지만 가새 의 사용은 증가되고 있는 반면에 접합부의 개념에 대한 이해 와 실례가 부족하여 적용에 적지 않은 어려움을 겪고 있는 실정이다.

또한 최근 건설 산업은 대형화, 고층화되고 그 형상이 복 잡해짐에 따라 기존의 $2 \mathrm{D}$ 기반의 정보 교환 방식으로는 건 설 산업의 각 분야에서 발생되는 방대한 양의 데이터를 처리 하기에는 한계에 다다르게 되었다. 이에 3D 객체 모델을 중 심으로 각 분야에서 생산되는 데이터를 통합하여 저장하고, 이를 공유하여 업무의 효율성을 제고하기 위한 노력의 일환 으로 BIM(Building Information Modeling) 기술이 발전 되었다 ${ }^{[3]}$. 이러한 $\mathrm{BIM}$ 을 위해 중요한 것은 각각의 전문분야 에서 사용되는 소프트웨어들 간에 한번 생성된 건물정보를 서로 교환하고 공유하는 것이다. 하지만 각 전문분야에서 사 용하는 어플리케이션(application)이 상이함에 따라 정확한 정보의 교환이 이루어지지 않기 때문에 정보의 손실이 발생 
되고, 이러한 문제점들은 $\mathrm{BIM}$ 을 접근하는데 어려움을 야기 시키고 있다 ${ }^{[4]}$. 따라서 BIM모델의 활용을 위해서는 각 전문 분야가 다양한 $\mathrm{BIM}$ 어플리케이션을 활용하여 생성된 정보들 간의 상호연동성 확보가 필수적이다. 그래서 현재에는 $\mathrm{BIM}$ 을 지원하는 소프트웨어 벤더들에 의해API (Application Programming Interface)와 같은 기술의 지원으로 인해 그 기술 개발이 더욱 용이해지고 있으며 다양한 분야에서 적용 되어지고 있다 ${ }^{[5]}$.

\section{2 연구의 목적}

본 연구는 강구조물의 실시설계 단계에서 접합부의 구조설 계 및 BIM 모델링의 효율성을 제고하기 위한 것으로 브레이 스 접합부의 구조설계 인터페이스 모듈 개발을 목적으로 한 다. 이를 위하여 국내·외의 구조설계기준을 분석하여 접합부 구조설계 프로그램을 구축하였으며, BIM 설계 도구와 연동 하여 모델 데이터로부터 구조설계를 수행하기 위한 입·출력 데이터를 자동으로 생성하며, 구조설계 결과로부터 BIM 모델을 자동으로 생성할 수 있는 인터페이스 모듈을 개발 하였다.

\section{3 연구의 범위}

본 연구는 철골 구조물의 브레이스 접합부를 대상으로 한 다. 이는 거셋플레이트에 브레이스를 설치하는 형태로서 국내 에서 일반적으로 적용되는 유형을 선택하였다. 브레이스 접합 부의 유형을 다음과 같이 세 가지로 분류하였다. 거셋 플레이 트(gusset plate)가 보, 기둥에 모두 용접된 경우(Case1), 보에만 용접된 경우(Case2), 기둥에만 용접되어 있는 경우 (Case3)로 나누어 설계가 이루어 졌다.

이 세 가지 유형 대해서만 구조해석 인터페이스 모듈에 적 용하였고, 구조 해석을 통해 강도를 검증하고, 그 결과를 리 포트 형식으로 출력하기 까지를 연구의 범위에 포함한다. 접 합부 3가지 유형은 Fig. 1과 같다.

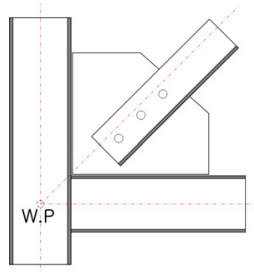

(a) Case 1

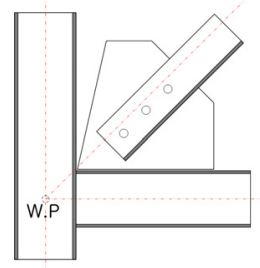

(b) Case 2

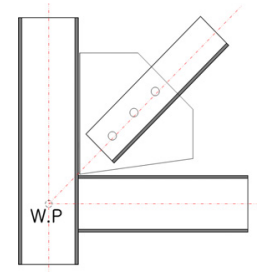

(c) Case 3
Fig. 1 Connection type of braces

\section{4 연구의 방법 및 절차}

본 연구는 브레이스 접합부의 구조설계 인터페이스 모듈의 개발에 관한 것으로 연구의 절차는 Fig. 2 와 같다.

먼저, 이론적 고찰을 통해 구조설계 프로그램과 인터페이 스 모듈 개발을 위해 사용되어진 Open API에 대하여 분석 하고, 이를 통해 $\mathrm{API}$ 의 개념과 구조에 대해 전반적으로 이해 하였다.

다음은 브레이스 접합부의 구조설계 프로그램을 구축하였 다. 프로그램 구축에 앞서 국내에서 일반적으로 사용되고 있 는 브레이스 접합부를 대상으로 기둥보의 접합면을 기준으 로 세 가지 형태로 분류하였으며, 각각의 형태에 대하여 국 내·외 구조설계 기준을 분석하여 설계 요구사항을 검토하였 다. 설계 기준은 국내의 $\mathrm{KBC}$ (Korean Building Code) 2009 기준과 미국의 AISC(American Institute of Steel Construction) 2005 기준을 적용하였다. 연구에서는 설계 요구사항 검토 결과를 바탕으로 국내에서 적합한 구조설계 알고리즘(또는 프로세스)을 고안하였으며, 세 가지 유형을 모 두 지원할 수 있는 구조설계 프로그램을 공학용 솔루션인 $\mathrm{MathCAD}$ 를 이용하여 구축하였다. 구축된 프로그램의 신뢰 성을 검증하기 위하여 상용 접합부 전용 구조설계 소프트웨 어인 Ram Connection ${ }^{[6]}$ (이하, RAM)을 이용하여 설계 결 과를 비교 - 검토하였으며, 이 RAM은 $\mathrm{AISC} 2005$ 기준을 적 용하고 있다.

다음은 BIM 모델과 연동하여 구조설계 프로그램의 입·출 력 데이터를 자동으로 생성하며, 구조설계의 수행 결과로부터 BIM 도구에서 접합부 모델을 자동으로 생성할 수 있는 인터

\section{Study of Software OpenAPI}

Details Design of Connection

- Build of Design Program for Connection

- Verification

Development of Interface Module for Connection Design

- Analysis of Data Structures of Input and Output

- Establishment of Interface Module

Performance and Analysis of Interface Module

- Selection of Steel Structures and Accomplishment of Program

- Verification of Structural Analysis

\section{Conclusion}

Fig. 2 Research flow 
페이스 모듈을 개발하였다. 본 연구에서 적용한 BIM 도구는 강구조물의 실시설계에서 가장 일반적으로 사용되는 Tekla Structures(이하, TEKLA)를 이용하였다 ${ }^{[7],[8],[9]}$. 연구에서 는 TEKLA와 구조설계 프로그램을 연동하기 위하여 TEKLA 에 포함된 브레이스 접합부의 컴포넌트에 대한 입·출력 파 라미터를 분석하였으며, 구축된 구조설계 프로그램의 입·출 력 멤버 변수와 매핑(mapping)하여 양방향으로 연동할 수 있는 데이터 구조를 작성하였으며, 이를 바탕으로 인터페이스 모듈을 개발하였다. 인터페이스 모듈의 개발은 닷넷 프레임워 크(DotNET Frame work 4.0) 개발 환경인 Visual C\# 2010(Express Edition)을 이용하였으며 ${ }^{[10]}$, TEKLA, MathCAD와의 데이터 연동을 위해 각각 Tekla OpenAPI, MathCAD API를 이용하였다 ${ }^{[11]}$. OpenAPI와 MathCAD $\mathrm{API}$ 는 DLL형태로 제공되며, 모두 닷넷 환경에서 구동되어 진다. 마지막으로 $3 \mathrm{D}-2 \mathrm{BAY}$ 의 비교적 단순한 예제 모델을 대상으로 연구를 통해 개발된 인터페이스 모듈을 적용하여 실시설계를 수행하였으며, 그 결과로부터 적용성 및 효율성을 분석하였다.

\section{Software OpenAPI의 고찰}

OpenAPI는 데이터의 개방 및 공유를 구현할 수 있는 핵 심 기술로써 데이터의 공유와 활용을 증대시킬 수 있고, 데이 터베이스를 별도로 구축할 필요 없이 시간과 비용을 절감할 수 있다. 그래서 본 연구에서 소프트웨어간 정보공유를 위해 3가지의 OpenAPI를 사용한다. Tekla OpenAPI, MathCAD API, itextSharp API중에 Tekla OpenAPI는 TEKLA와 관련된 업무 분야들과의 협업을 제공하기 위해 벤더에서 제

Table 1. Software DLL files

\begin{tabular}{|c|c|}
\hline Type of DLL & Content \\
\hline $\begin{array}{c}\text { Tekla.Structur } \\
\text { es.Model.dll }\end{array}$ & $\begin{array}{l}\text { Creation of object, consist of Class and } \\
\text { Mathod to control obiects, Namespace of } \\
\text { Tekla.structures.moldel, Tekla.structures. } \\
\text { Model.UI, include class of Beam, Countour, } \\
\text { BoltArray, Load, Component }\end{array}$ \\
\hline $\begin{array}{c}\text { Tekla.Structur } \\
\text { es.dll }\end{array}$ & $\begin{array}{c}\text { Consist of Class using to Modeling and } \\
\text { drawing to TEKLA, Namespace of } \\
\text { Tekla.Structures. Geometry 3D }\end{array}$ \\
\hline $\begin{array}{l}\text { Mathcad.Auto } \\
\text { mation } \\
\text { API.dll }\end{array}$ & $\begin{array}{l}\text { Mathcad.IMathcadWorksheet, } \\
\text { Mathcad.IMathcadWorksheets Class include } \\
\text { Mathod that create(Open }()) \text { Worksheet, } \\
\text { save }(\text { Close }()) \text {, print(Print }()) \text {, } \\
\text { import(SetValue }()) \text {, and export(GetValue }())\end{array}$ \\
\hline itextsharp.dll & $\begin{array}{c}\text { include Class of itextsharp.Document, } \\
\text { itextsharp.Font, itextsharp.Image, } \\
\text { itextsharp.Element and itextsharp.Chapter }\end{array}$ \\
\hline
\end{tabular}

공하는 오픈 소스이며, 사용자는 . $\mathrm{NET}, \mathrm{COM}$ 환경에서 이를 참조함으로써 외부에서 TEKLA의 기능과 모델 $\mathrm{D} / \mathrm{B}$ 에 접근 할 수 있다. OpenAPI는 모델(Model), 드로잉(Drawing), 스크립팅(Scripting)등의 DLL(Dynamic Linked Library : 동적링크라이브러리)로 구성되어 있으며 ${ }^{[3]}$, MathCAD $\mathrm{API}$ 는 워크시트(Worksheet)상에서 정보의 입출력과 계산 을 위한 기능구현이 가능한 DLL로 구성된다. itextsharp $\mathrm{API}$ 는 $\mathrm{PDF}$ 형식의 문서를 제공하기 위한 $\mathrm{API}$ 로써 문서 (Document), 폰트(Font), 요소(Element)등의 클래스를 포함한 DLL로 구성된다. DLL은 여러 함수의 공유 라이브 러리로 사용되는 실행 파일이다. 동적 링크를 사용하여 프로 세스에서 해당 프로세스의 실행 코드에 포함되지 않은 함수 를 호출할 수 있다. 함수의 실행 코드는 DLL에 있으며, DLL에는 이것을 사용하는 프로세스와는 별도로 컴파일, 링 크 및 저장되는 하나 이상의 함수가 포함되어 있고, 데이터와 리소스를 쉽게 공유할 수 있는 장점이 있다. 소프트웨어에서 제공하는 DLL의 종류는 Table 1과 같다.

\section{3. 브레이스 접합부의 구조상세설계}

\section{1 브레이스 접합부의 설계 개요}

본 연구에서는 앞에서 언급한 브레이스 접합부 형태를 세 가지로 분류하였으며, 각 형태에 따라 접합면에 작용하는 소 요강도(Interface Forces)를 산정하였다. 이에 따른 각 접 합면에서 필요한 설계요구사항을 검토하였다 ${ }^{[12]}$. 검토를 위해 서 $\mathrm{KBC} 2009$ 와 $\mathrm{AISC} 2005$ 기준을 적용하였고, 설계요구 사항은 다음 Table 2 와 같다.

\section{2 구조설계 프로그램 작성}

Table 2를 토대로 Fig. 3과 같이 구조해석을 위한 알고 리즘을 작성하였고, 이는 구조설계를 수행하기 위한 설계조건

Table 2. Design check list of brace connections

\begin{tabular}{c|c}
\hline Connection Type & Check Point \\
\hline $\begin{array}{c}\text { Interface of between } \\
\text { gusset plate and } \\
\text { brace }\end{array}$ & $\begin{array}{c}\text { Shear Strength of Bolt, Bearing of } \\
\text { Bolt, Block Shear, Tensile Yield }\end{array}$ \\
\hline $\begin{array}{c}\text { Interface of between } \\
\text { gusset plate and } \\
\text { girder }\end{array}$ & $\begin{array}{c}\text { Tensile Yield, Shear Yield, Block } \\
\text { Shear, Local Yielding }\end{array}$ \\
\hline $\begin{array}{c}\text { Interface of between } \\
\text { gusset plate and } \\
\text { culumn }\end{array}$ & $\begin{array}{c}\text { Tensile Yield, Shear Yield, Block } \\
\text { Shear, Local Yielding }\end{array}$ \\
\hline
\end{tabular}




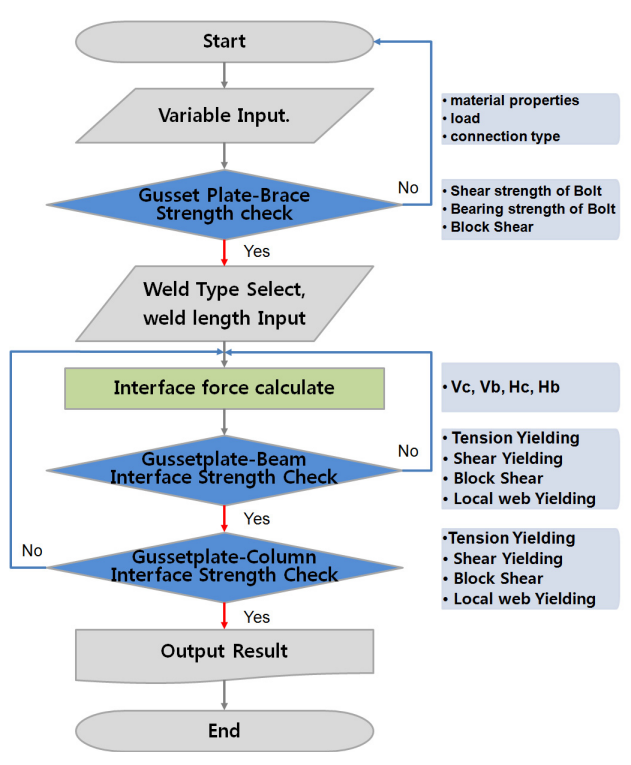

Fig. 3 Structural design flow chart

의 입력과정에서부터 설계결과를 출력하기까지의 일련의 과 정들을 포함하고 있다. 연구에서는 이를 바탕으로 구조해석프 로그램을 구축하였다. 이를 위해 공학용 솔루션인 MathCAD 를 사용하였다.

\section{3 구조설계 프로그램의 검증}

이렇게 구축된 브레이스접합부 구조설계프로그램의 검증을 위해서 국외에서 상용화된 접합부 프로그램인 RAM을 사용 하여 검증하였다. RAM에서는 브레이스접합부에 대해서 거 셋플레이트가 보, 기둥 모두 용접 접합된 형태만 제공하기 때 문에 본 연구에서 실시한 Case 1타입에 대한 구조해석 결과 를 비교검토 하였다. 설계조건은 Table 3과 같고 비교 검토 에 대한 결과는 Table 4-7과 같다.

21 개의 설계항목에 대해서 비교했을 때 값들이 거의 일치

Table 3. Member conditions

\begin{tabular}{|c|c|c|c|c|}
\hline \multirow{3}{*}{$\begin{array}{c}\text { Section } \\
\text { Conditon }\end{array}$} & Column & H steel & $\begin{array}{c}400 X 400 X 13 X \\
21\end{array}$ & SS400 \\
\hline & Beam & H steel & $\begin{array}{c}300 \times 300 \times 10 \mathrm{X} \\
15\end{array}$ & SS400 \\
\hline & Brace & L steel & 70X70X6X8.5 & SS400 \\
\hline \multirow{4}{*}{$\begin{array}{l}\text { Connec } \\
\text {-tion }\end{array}$} & \multirow{2}{*}{$\begin{array}{c}\text { Gusset } \\
\text { Plate }\end{array}$} & Thickness & $\mathrm{LH}$ & $\mathrm{LV}$ \\
\hline & & $8 \mathrm{~mm}$ & $200 \mathrm{~mm}$ & $320 \mathrm{~mm}$ \\
\hline & Bolt & \multicolumn{3}{|c|}{$\begin{array}{c}\text { bolt row }=2 \text {, bolt column }=1 \\
\text { Traverse edge distance }=40 \mathrm{~mm} \text {, } \\
\text { Longitudinal edge distance }=70 \mathrm{~mm} \\
\text { Bolt Type=10T, Diameter of Bolt }=\mathrm{M} 16\end{array}$} \\
\hline & Weld & \multicolumn{3}{|c|}{$\mathrm{D}=6.35 \mathrm{~mm}$, Weld Size of Connection } \\
\hline
\end{tabular}

Table 4. Comparison of design strength for interface between gusset plate and brace

\begin{tabular}{c|c|c|c}
\hline Type & $\begin{array}{c}\text { MathCAD } \\
(\mathrm{kN})\end{array}$ & $\begin{array}{c}\text { Ram Connection } \\
(\mathrm{kN})\end{array}$ & Comparison \\
\hline Shear Strength & 120.60 & 120.60 & 100 \\
\hline Bearing Strength & 138.24 & 138.24 & 100 \\
\hline Block Shear & 142.74 & 130.88 & 110 \\
\hline Yielding gross area & 171.89 & 171.89 & 100 \\
\hline $\begin{array}{c}\text { Rupture effective } \\
\text { net area }\end{array}$ & 152.82 & 150.34 & 101 \\
\hline Tension yielding & 136.76 & 136.76 & 100 \\
\hline
\end{tabular}

Table 5. Comparison of Interface forces

\begin{tabular}{c|c|c|c}
\hline Type & MathCAD(kN) & Ram Connection(kN) & Comparison \\
\hline$H_{b}$ & 20.02 & 20.02 & 100 \\
\hline$H_{c}$ & 36.65 & 36.65 & 100 \\
\hline$V_{b}$ & 27.41 & 27.41 & 100 \\
\hline$V_{c}$ & 29.15 & 29.15 & 100 \\
\hline$M_{b}$ & 0 & 0 & 100 \\
\hline$M_{c}$ & $1.015 \times 10^{-15}$ & 0 & 100 \\
\hline
\end{tabular}

Table 6. Comparison of design strength for interface between gusset plate and beam

\begin{tabular}{c|c|c|c}
\hline Type & $\begin{array}{c}\text { MathCAD } \\
(\mathrm{kN})\end{array}$ & $\begin{array}{c}\text { Ram Connection } \\
(\mathrm{kN})\end{array}$ & Comparison \\
\hline Tension yielding & 336.62 & 336.62 & 100 \\
\hline Shear yielding & 222.62 & 224.41 & 100 \\
\hline Welding strength & 210.12 & 503.38 & 42 \\
\hline Block shear & 1656.00 & 1656.39 & 100 \\
\hline Local web Yielding & 661.41 & 661.4 & 100 \\
\hline
\end{tabular}

Table 7. Comparison of design strength for interface between gusset plate and column

\begin{tabular}{c|c|c|c}
\hline Type & $\begin{array}{c}\text { MathCAD } \\
(\mathrm{kN})\end{array}$ & $\begin{array}{c}\text { Ram Connection } \\
(\mathrm{kN})\end{array}$ & Comparison \\
\hline Tension yielding & 536.97 & 539.66 & 100 \\
\hline Shear yielding & 359.78 & 359.77 & 100 \\
\hline Welding strength & 345.50 & 807.01 & 43 \\
\hline Block shear & 3107.00 & 3106.67 & 100 \\
\hline Local web Yielding & 1631.00 & 1631.21 & 100 \\
\hline
\end{tabular}

※ MathAD : KBC-09 Standard, Ram Connection : AISC standard

※ Mothod of Comparison value Calculation :

$\left(\frac{\text { Math Cad }}{\text { Ram Connection }} X 100\right) \%$ 
했지만 차이가 발생한 용접부의 설계강도에 대한 설명은 다 음과 같다.

국내기준에 따른 용접부의 내력은 기본적으로 사용성한계 상태에 기본을 두고 설계한다. 즉 용접부의 강도는 모재와 용 착된 용접재료의 강도에 의해 지배를 받는다.

용착된 용접재료의 강도가 모재의 재료강도보다 낮을 경우 용접재의 강도에 지배를 받지만 국내의 기준은 용접재가 모 재의 강도보다 큰 상태가 되도록 하여 설계식은 항상 모재의 강도를 기본으로 하여 설계한다 ${ }^{[13],[14],(15]}$. 반면에 국외의 AISC2005기준에서 용접부의 강도는 용접재의 인장파단, 전 단파단 또는 전단항복의 강도한계상태에 따라 설계한다 ${ }^{[16]}$. 따라서 용접부의 강도는 국내·외의 기준이 해석하는 방식에 있어 차이가 있음을 알 수 있다.

다음은 국내기준에 따른 용접부의 설계강도는 $\phi R_{n}$ 은 전 단항복의 사용성한계상태에 따라서 식 (1)과 같다.

$$
\begin{aligned}
& \phi=0.9 \\
& R_{n}=F_{w} \cdot A_{w}
\end{aligned}
$$

여기서, $F_{w}$ : nominal strength of base metal, $\mathrm{MPa}$

$$
A_{w} \text { : effective net area, } \mathrm{mm}^{2}
$$$$
F_{w}=0.6 \cdot F_{y}
$$

또한, 국외기준(AISC2005)에 따른 용접부 설계 강도는 식 (2)와 같이 강도한계상태에 따라 설계한다.

$$
\begin{aligned}
& \phi=0.75 \\
& R_{n}=F_{w} \cdot A_{w}
\end{aligned}
$$

여기서, $F_{w}$ : nominal strength of electrode

$A_{w}$ : effective net area, $\mathrm{mm}^{2}$

$F_{w}=0.6 \cdot F_{E X X}\left(1.0+0.5 \sin \theta^{1.5}\right)$

$A_{w}=t_{a} \cdot l$

$F_{E X X}$ : Electrode classification number, ksi (in study, apply $70 \mathrm{ksi}$ )

$\theta$ : brace with the vertical angle

\section{4. 입출력 포맷의 데이터 구조분석 및 구축}

\section{1 입출력 포맷의 데이터 구조분석}

Tekla Structures의 Data구조분석은 주부재의 Data정
보분석과 접합부 구성요소의 멤버 변수를 추출하는 것으로 나뉜다. 주부재의 Data는 TEKLA에서 제공하는 Tekla.
(2)

(4)

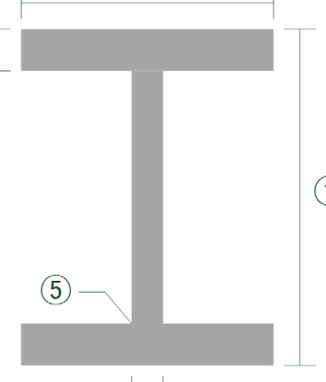

(3)

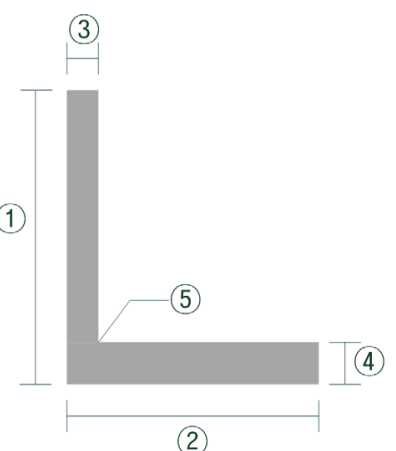

(2) (a) Shape data of $\mathrm{H}$ section (b) Shape data of angle

Fig. 4 Geometry information of $\mathrm{H}$ and $\neg$ sections

Table 8. Beam class data

\begin{tabular}{c|c|c|c}
\hline Class & Data & Description & Data Type \\
\hline \multirow{4}{*}{ Beam } & MaterialString & $\begin{array}{c}\text { material of } \\
\text { member }\end{array}$ & string \\
\cline { 2 - 4 } & HEIGHT & $\begin{array}{c}\text { Fig 4.(a)-(1), } \\
\text { (b)-(1) }\end{array}$ & double \\
\cline { 2 - 4 } & WIDTH & $\begin{array}{c}\text { Fig 4.(a)-(2), } \\
\text { (b)-(2) }\end{array}$ & double \\
\cline { 2 - 4 } & FLANGE_THICKNESS & Fig 4.(a)-(4) & double \\
\cline { 2 - 4 } & ROUNDING_RADIUS_1 & $\begin{array}{c}\text { Fig 4.(a)-(5), } \\
\text { (b)-(5) }\end{array}$ & double \\
\cline { 2 - 4 } & CROSS_SECTION_AREA & $\begin{array}{c}\text { cross section of } \\
\text { member }\end{array}$ & double \\
\cline { 2 - 4 } & FLANGE_THICKNESS_1 & Fig 4.(b)-(3) & double \\
\cline { 2 - 4 } & FLANGE_THICKNESS_2 & Fig 4.(b)-(4) & double \\
\hline
\end{tabular}

Table 9. Parameter analysis of connections

\begin{tabular}{c|c|c|c}
\hline \multirow{4}{*}{ Component } & \multicolumn{2}{|c|}{ Parameter name } & \multicolumn{2}{|c}{ description } \\
\cline { 2 - 3 } & Tekla & Type & \\
\hline \multirow{4}{*}{ Plate } & adist4 & double & Plate Width \\
\cline { 2 - 4 } & col & double & Plate Depth \\
\cline { 2 - 4 } & tpl2 & double & Plate Thickness \\
\cline { 2 - 4 } & mat2 & string & Plate Material \\
\hline \multirow{5}{*}{ Bolt } & diameter & Int & Bolt Diameter \\
\cline { 2 - 4 } & screwdin & string & Bolt Type \\
\cline { 2 - 4 } & nb & Int & The number of Bolt Column \\
\cline { 2 - 4 } & nw & Int & The number of Bolt Row \\
\cline { 2 - 4 } & lbd & string & Pitch \\
\cline { 2 - 4 } & rb1 & double & Longitudinal edge distance \\
\cline { 2 - 4 } & lwd & string & Gage \\
\hline
\end{tabular}


Table 10. Definition of MathCAD parameters

\begin{tabular}{|c|c|c|c|c|}
\hline Interface & Part & Name & Descrition & $\begin{array}{l}\text { Data } \\
\text { Type }\end{array}$ \\
\hline \multirow{2}{*}{$\begin{array}{c}\text { W } \\
0\end{array}$} & \multirow{7}{*}{$\begin{array}{c}\mathrm{C} \\
\mathrm{o} \\
\mathrm{l} \\
\mathrm{u} \\
\mathrm{m} \\
\mathrm{n}\end{array}$} & $\mathrm{Hc}$ & Fig 4. (a)-(1) & double \\
\hline & & $\mathrm{Bc}$ & Fig 4.(a)-(2) & double \\
\hline \multirow{2}{*}{$\begin{array}{l}\mathrm{r} \\
\mathrm{k}\end{array}$} & & tcw & Fig 4.(a)-(3) & double \\
\hline & & tcf & Fig 4.(a)-(4) & double \\
\hline \multirow{2}{*}{$\begin{array}{l}\mathrm{S} \\
\mathrm{h} \\
\mathrm{e}\end{array}$} & & $\mathrm{rc}$ & Fig 4.(a)-(5) & double \\
\hline & & Acg & cross section of member & double \\
\hline \multirow[t]{2}{*}{$\begin{array}{l}\mathrm{e} \\
\mathrm{t}\end{array}$} & & co_mat & material of member & string \\
\hline & & c_section & type of member & string \\
\hline
\end{tabular}

Table 11. Data convert format

\begin{tabular}{c|c|c|c|c}
\hline \multirow{2}{*}{ Part } & MathCAD & Tekla & $\begin{array}{c}\text { Interface } \\
\text { Module }\end{array}$ & $\begin{array}{c}\text { Data } \\
\text { Type }\end{array}$ \\
\hline \multirow{4}{*}{$\mathrm{C}$} & $\mathrm{Hc}$ & HEIGHT & $\mathrm{H}$ & double \\
\cline { 2 - 5 } & $\mathrm{Bc}$ & WIDTH & $\mathrm{B}$ & double \\
\cline { 2 - 5 } 0 & $\mathrm{tcw}$ & WEB_THICKNESS & $\mathrm{TW}$ & double \\
\cline { 2 - 5 } $\mathrm{l}$ & $\mathrm{tcf}$ & FLANGE_THICKNESS & $\mathrm{TF}$ & double \\
\cline { 2 - 5 } $\mathrm{u}$ & $\mathrm{rc}$ & ROUNDING_RADIUS_1 & $\mathrm{R}$ & double \\
\cline { 2 - 5 } $\mathrm{m}$ & $\mathrm{Acg}$ & CROSS_SECTION_AREA & $\mathrm{A}$ & double \\
\cline { 2 - 5 } $\mathrm{n}$ & co_mat & MaterialString & Material & string \\
\cline { 2 - 5 } & c_section & ProfileString & COL & string \\
\hline
\end{tabular}

Structures.Model.DLL의 구성클래스 중 부재, 접합부의 속성 정보를 알기위해 관련된 클래스를 대상으로 데이터 구 조를 분석하였고, Beam클래스 Data는 Table 8과 같다. 또한 OpenAPI의 함수를 통해 접합부의 정보를 저장하고 내 보내는 것을 직접 콘트롤하기 위해서 접합부 구성요소의 멤 버 변수를 파악하였다.

Table 9는 본 연구에서 필요한 파라미터를 분석한 결과이 다. MathCAD는 워크시트로부터 정보를 입출력하는 방식으 로써 사용자가 구조해석을 위해 관련된 정보들을 지정하여 변수이름을 정의하였다. Table 10은 MathCAD의 변수들을 정의하여 일부를 표로 나타낸 것이다.

\section{2 데이터 변환 포맷 구축}

인터페이스 모듈에서 TEKLA의 모델 정보와 MathCAD 의 정보의 교환을 위해서는 각각의 소프트웨어에서 받아들 일 수 있는 형태로 변환되어야 할 필요가 있다. 앞서 실시 한 두 소프트웨어의 입 - 출력 데이터 구조의 분석결과를 통 해 관련된 속성을 매핑(Mapping)하여 데이터 변환 포맷을 구축하였다. Table 11은 데이터 변환 포맷의 일부를 나타 낸 것이다.

\section{5. 인터페이스 모듈 개발}

\subsection{BIM기반의 Process}

본 연구에서는 Fig. 5와 같이 실시설계 단계에서 효율성을 제고하기 위해서 BIM기반으로 한 Process고안하였다. 이는 사용자가 직접 구조해석을 위해 정보를 입력하지 않고 3D모 델과 구조해석 모듈간의 정보공유를 통해 업무의 자동화를 실현하고자 하였다.

\section{2 브레이스 접합부 인터페이스 모듈 개발}

위 Fig. 5의 Process를 바탕으로 하여 인터페이스 모듈을 개발하였고 인터페이스 모듈의 수행 흐름은 Fig. 6과 같다. 브레이스 접합부 구조설계 인터페이스 모듈의 흐름은 크게 두 개의 Process로 구분한다 ${ }^{[17]}$. TEKLA와 MathCAD의 정보 를 공유하고 이를 바탕으로 구조해석이 수행되는 Process 1 과 인터페이스 모듈에서 직접 구조해석을 수행하는 Process 2로 나눈다.

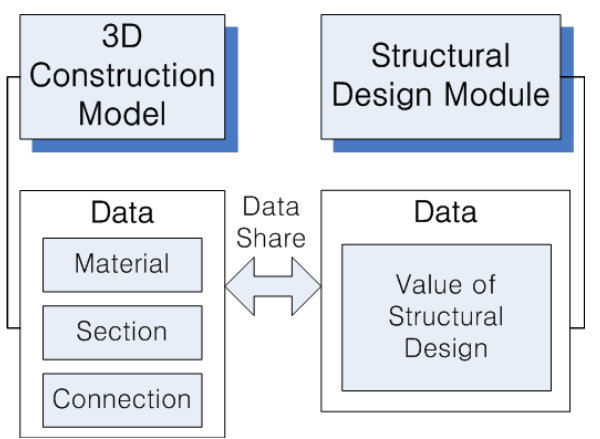

Fig. 5 BIM based process in the CD stage

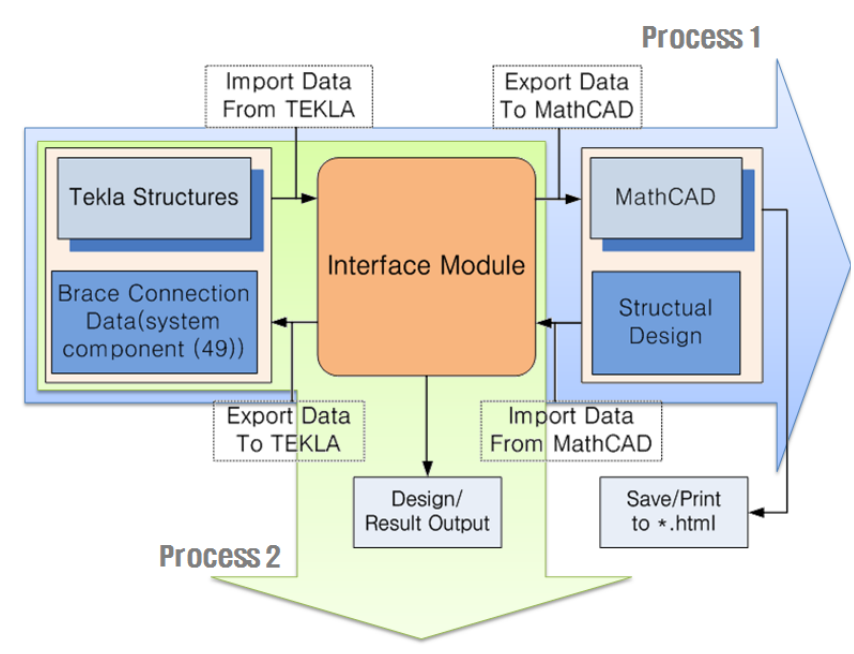

Fig. 6 Performance flow of interface module 


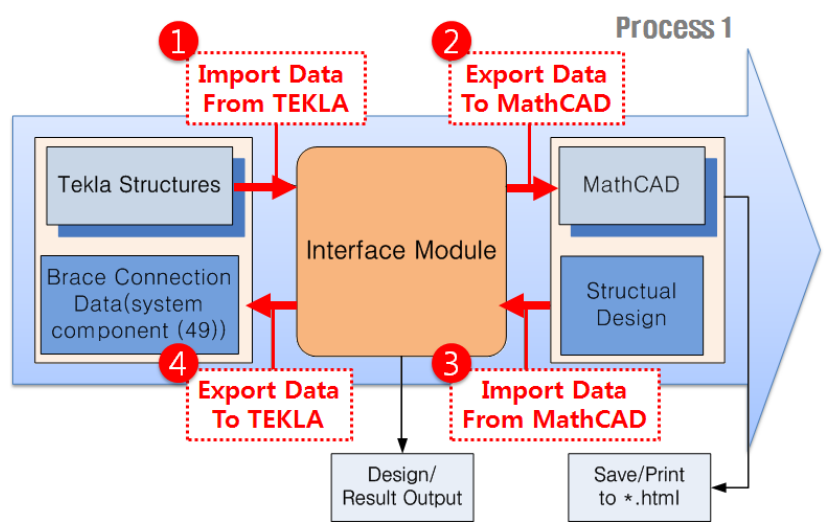

Fig. 7 Performance flow of process 1

\begin{abstract}
Mathcad.Application mc = new Mathcad.Application();
Mathcad.Worksheets wk;

Mathcad.Worksheet ws = new Mathcad.Worksheet();

//export to Column Property of Mathcad

ws.SetValue("Hc", BC.Column.H);

ws.SetValue("Bc", BC.Column.B);

ws.SetValue("tcw", BC.Column.TW);

ws.SetValue("tcf", BC.Column.TF);

.......

ws.Recalculate();

ws.Close(Mathcad.MCSaveOption.mcDiscardChanges);

System.Runtime.InteropServices.Marshal.ReleaseComObject(wk);

System.Runtime.InteropServices.Marshal.ReleaseComObject(ws);

System.Runtime.InteropServices.Marshal.ReleaseComObject(mc);
\end{abstract}

Fig. 8 Coding to create of MathCAD sheet

\subsubsection{Process 1 의 흐름}

Process 1의 흐름은 Fig. 7과 같고, 인터페이스 모듈의 진행은 그림에서 표시된 번호순서대로 수행한다. 먼저 Fig. 7-(1)의 과정은 TEKLA상의 모델 데이터를 인터페이스 모듈 로 불어온다.

Fig. 7-(2)의 과정에서는 인터페이스 모듈에서 저장된 데이 터를 구조해석 모듈인 MathCAD로 전달한다. 입력받은 정 보를 통해 구조해석을 수행하게 된다.

Fig. 8은 MathCAD상의 구조해석 모듈을 불러오고, 값 을 할당하는 과정에 관해서 실제로 프로그래밍한 것 중 일부 분이다.

(3)의 과정은 구조해석을 수행 한 후 그 결과 값을 다시 인 터페이스 모듈로 저장한다. 이때 구조해석 결과를 요약한 정 보를 인터페이스 모듈에서 나타낸다. (4)의 과정은 인터페이스 모듈에 수정되어 저장된 정보가 TEKLA상의 접합부 모델에 자동으로 반영하여 모델링하게 된다.

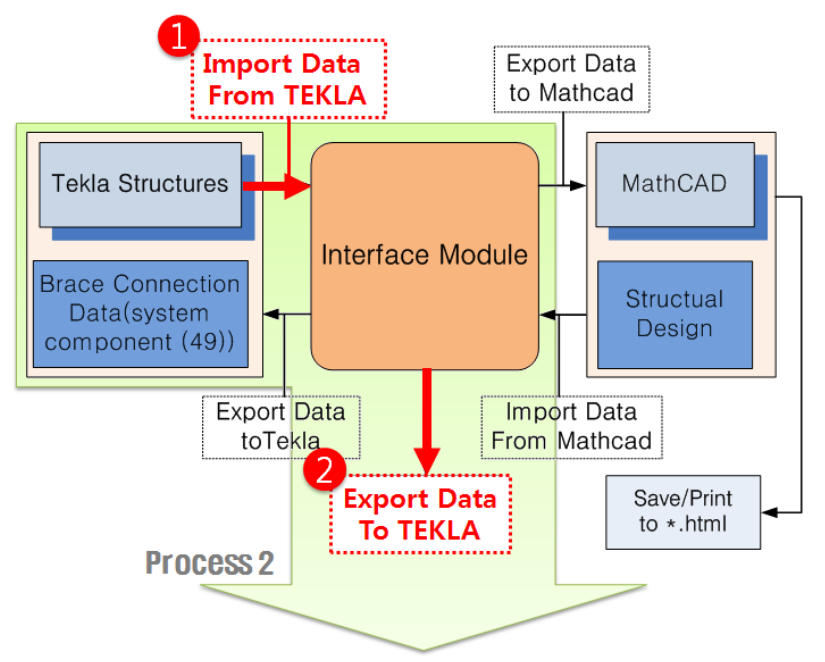

Fig. 9 Performance flow of process 2

\section{PdfPCell C;}

Document document $=$ new Document(PageSize.A4);

PdfWriter writer $=$ PdfWriter.GetInstance(document, new

FileStream("Brace_Conection_data.pdf", FileMode.Create)); document.Open();

Paragraph Title = new Paragraph ("Brace Connection Design ", title);

PdfPTable table1 = new PdfPTable(3);

$\mathrm{C}=$ new PdfPCell();

C.Border = iTextSharp.text.Rectangle.NO_BORDER;

tablel.AddCell(C);

document.Add(Title);

PDF2.LoadFile("Brace_Conection_data.pdf");

Fig. 10 Coding to execute the analysis function of interface module

\subsubsection{Process 2의 흐름}

Process 2에서 TEKLA 모델로부터 정보를 추출하는 단 계는 Process 1과 동일한 과정을 거친다. 앞서 행한 Process 1은 MathCAD를 구조 해석 코어로 사용했지만, 이는 MathCAD와 정보공유를 생략하고 인터페이스 모듈에 서 직접 구조해석을 수행한다. Process 2의 수행 흐름은 Fig. 9와 같다. Fig. 10은 인터페이스 모듈의 구조해석 기 능을 추가하기 위해서 프로그래밍 한 것으로써, $\mathrm{PDF}$ 파일 형 식으로 정보를 입출력 받는다.

위에서 제안한 Process를 바탕으로 개발된 인터페이스 모 듈 UI는 다음 Fig. 11과 같으며, 주요 기능은 정보를 입 · 출력하는 기능, 입·출력된 정보를 표시하는 창으로 나뉜다. 세부 기능의 설명은 다음 장에서 계속해서 설명하겠다. 


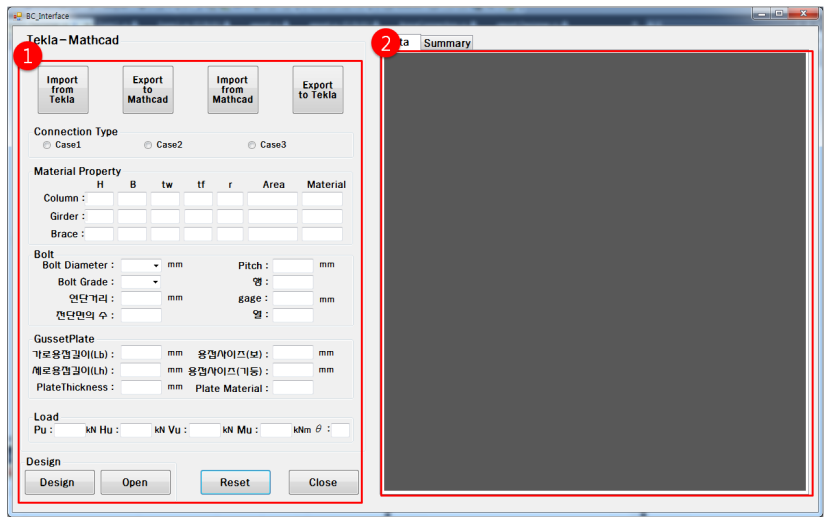

Fig. 11 UI(User interface)

\section{6. 개발 모듈 수행 및 검증}

\section{1 수행 대상 및 범위}

본 연구에 개발한 프로그램을 검증하기 위해 $3 \mathrm{D}-2 \mathrm{BAY}$ 의 TEKLA 샘플 모델을 대상으로 인터페이스 모듈을 적용하여 접합부의 구조계산 및 강도 검증을 검토하였다. 예제모델과 부재정보는 Fig. 12 와 Table 3과 같다.

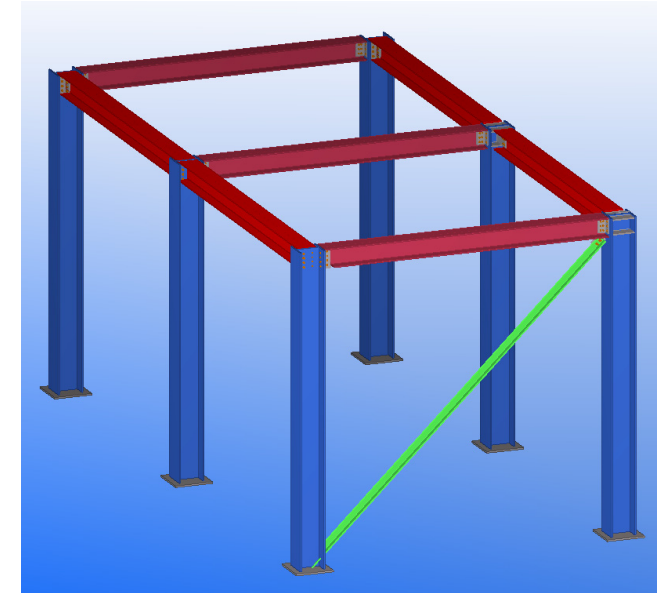

Fig. 12 Sample model of 3D-2BAY (Picture source of TEKLA)

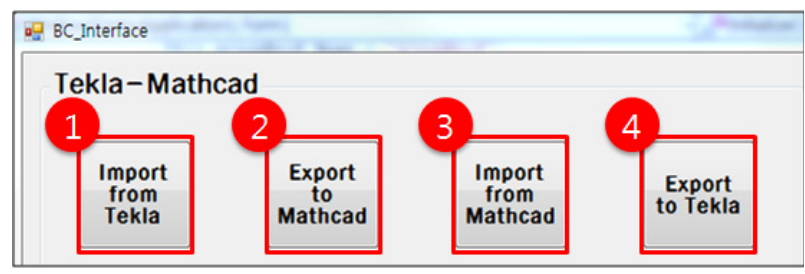

Fig. 13 Function buttons of interface module

\section{2 수행 및 결과 도출}

Process 1의 수행흐름에 맞춰 인터페이스 모듈을 수행하 였다. 먼저 Fig. 13-1)을 실행시키면 TAKLA 모델로부터 구조해석을 위한 정보를 불러온다. 정보를 불러오기 위해서는 Fig. 13에 표시된 순서로 부재를 선택한다. 이 정보는 Fig. 15에 저장이 되고, 이를 바탕으로 Fig.11-(2)에 PDF파일로 표시된다. 이는 파일을 저장하거나 출력이 가능하도록 하였다.

Fig. 13-(2)를 실행하게 되면 TEKLA로부터 불러들인 정 보를 구조해석모듈인 MathCAD로 전달하게 된다. Fig. 16 과 같이 MathCAD상에 입력된 정보를 확인할 수 있다. 소 요하중, 부재 정보, 접합부의 대한 정보, 설계 강도를 검증한 결과등을 나타낸다 ${ }^{[18]}$. 이때 구조해석 검증을 통해 결과가 만

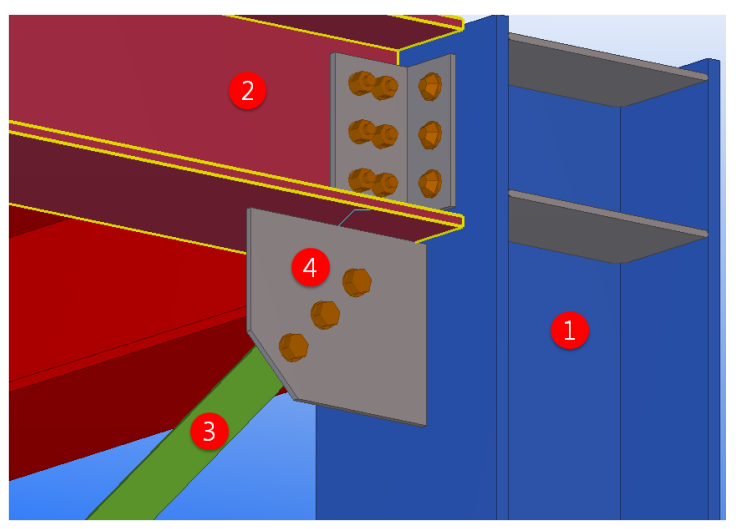

Fig. 14 Selection sequence of members(TEKLA)

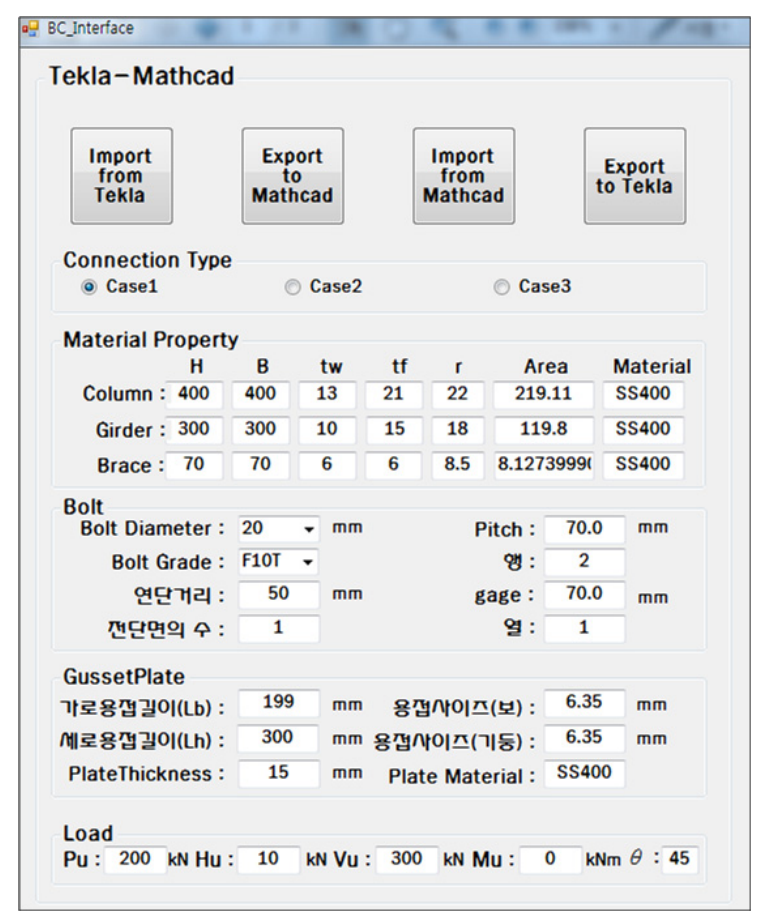

Fig. 15 Stored information in interface module 


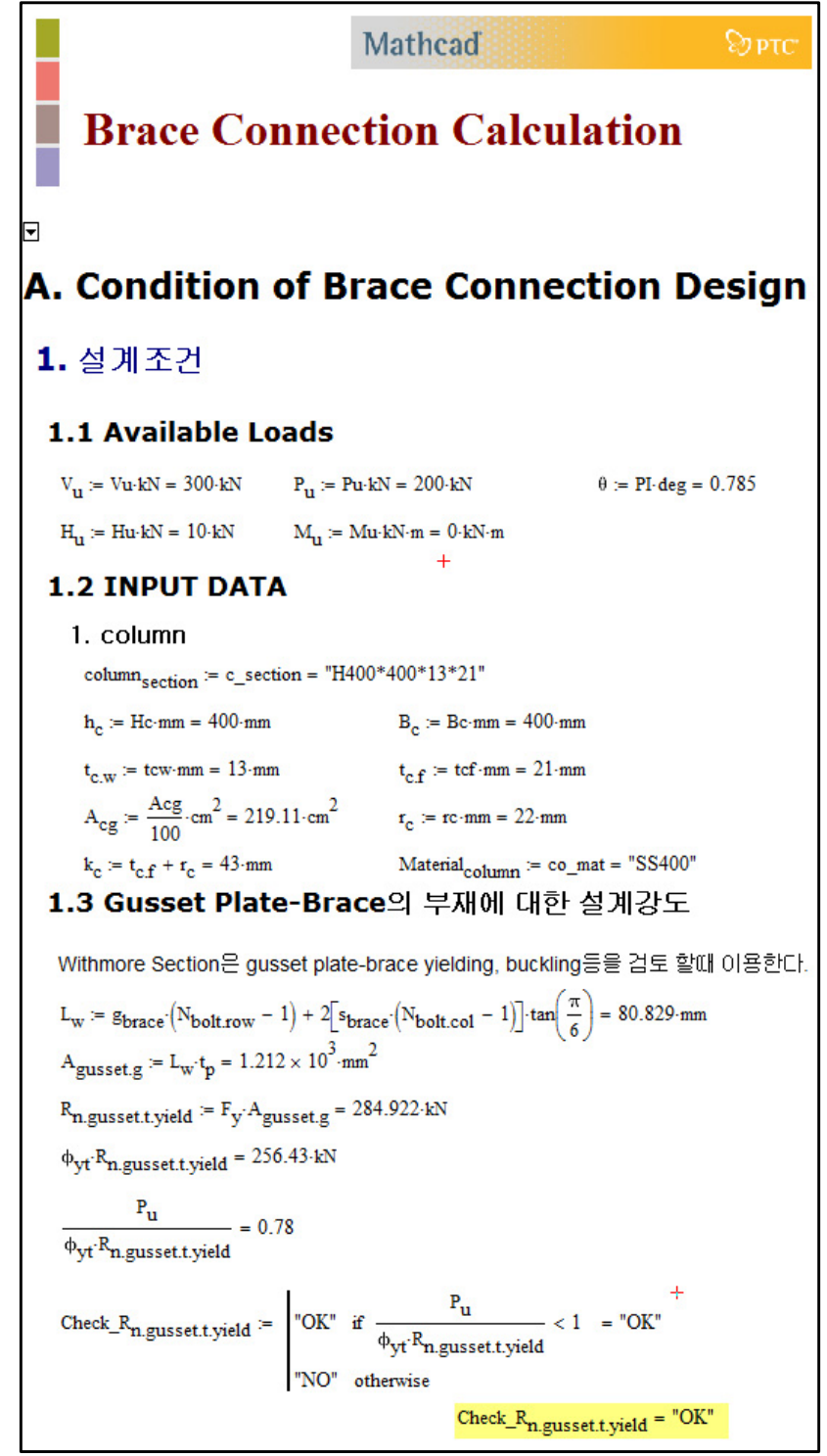

Fig. 16 Structural analysis module(MahCAD WorkSheet)

족하지 못했을 땐 인터페이스 모듈 상에 사용자가 원하는 정 보를 수정하고, 수정된 정보를 통해 다시 구조해석을 수행하 게 된다.

Fig. 13-(3)을 실행하면 구조해석모듈로 부터 구조해석 및 검증이 끝난 정보를 인터페이스 모듈로 다시 저장한다. 11(2)의 Summary창에 구조해석에 대한 Summary정보를 기 록한다. 이때 $\mathrm{PDF}$ 파일 형식으로 기록되어 저장 또는 출력이 가능하다.

마지막으로 Fig. 13-(4)를 실행하면 TEKLA의 접합부 모 델로 수정된 정보를 반영하게 된다.

다음은 Process 2의 수행흐름에 맞춰 인터페이스 모듈을 수행하였다. Process 1의 수행흐름에서 TEKLA로 부터 추 출한 정보를 인터페이스 모듈로 저장하는 방법은 Fig. 13 15 와 같다.

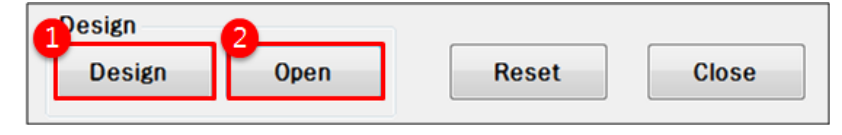

Fig. 17 Structural analysis of interface module

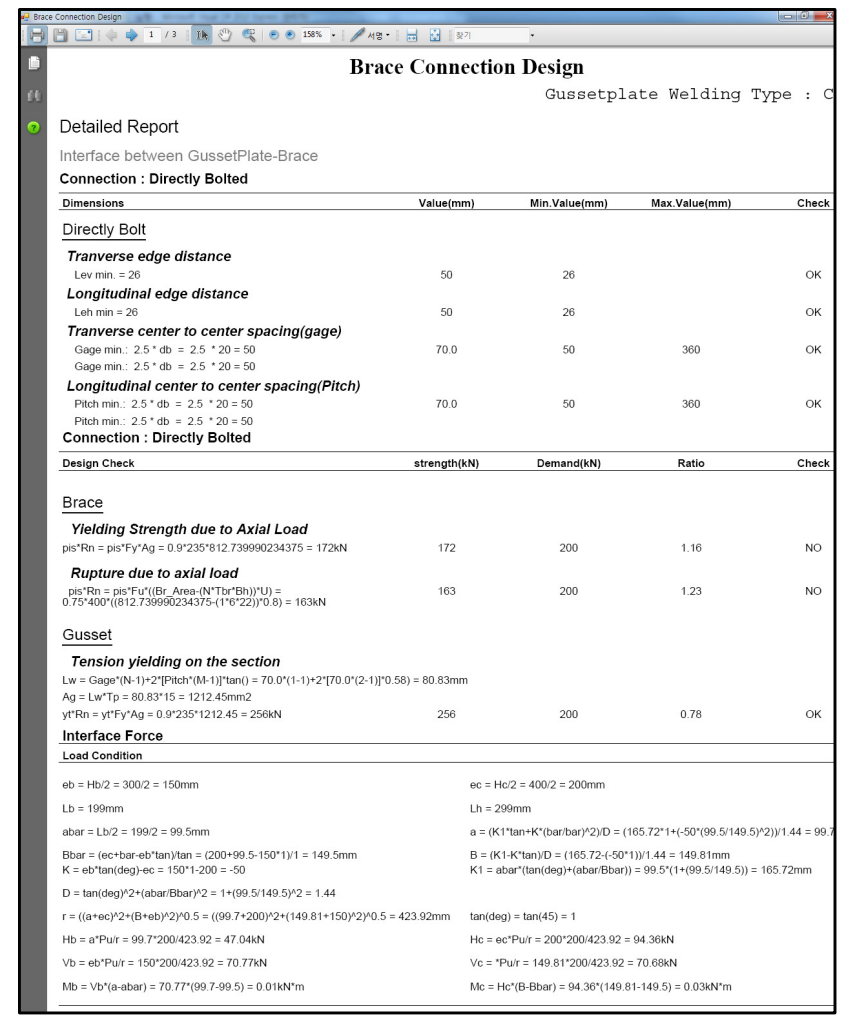

Fig. 18 Structural analysis results recorded by PDF file

여기에서 Fig. 17-(1)을 실행하면 인터페이스 모듈에 저장 된 정보를 적용하여 구조해석을 실시하고 이를 $\mathrm{PDF}$ 파일로 기록한다. 이때 $\mathrm{PDF}$ 형식으로 기록된 구조 해석결과는 저장 하거나 출력이 가능하다. 또한 사용자가 구조해석 결과를 보 기 편리하도록 설계식, 설계강도, 소요강도, 강도비, 강도비 체크 순으로 기록하였다. Fig. 18 은 구조해석 결과가 PDF 형식으로 나타난 결과이다.

\section{7. 결 론}

본 연구에서는 구조상세모델과 구조해석을 위한 소프트웨 어간의 연동을 통해 브레이스 접합부의 구조 설계 및 강도 검증이 가능한 인터페이스 모듈을 개발하였다. 여기에서 사용 자의 편리와 구조상세모델 정보의 사용성을 극대화시키기 위 해 인터페이스 모듈자체에서 구조해석이 가능한 기능을 추가 하였다. 이를 예제 모델을 통해 구조설계 인터페이스 모듈의 사용성과 효율성을 검증하였다. 이상의 연구로부터 얻은 결론 은 다음과 같다. 
(1) 본 연구에서는 국내에서 자주 사용되는 브레이스 접합부 의 3가지 타입에 대한 구조설계를 수행하였고, 이는 국 내 기준을 적용하여 국내에서 사용하기 적합한 브레이스 접합부 구조설계 방법을 제시하였다. 이번 연구로 인해 브레이스 접합부의 구조설계의 한 방법을 제시함으로써 브레이스 접합부에 대한 이해도가 넓어질 것으로 기대된다.

(2) 최근 건물이 복잡화, 고층화되면서 많은 관심이 집중되 고 있는 $\mathrm{BIM}$ 기술을 적용하였다. $3 \mathrm{D}$ 로 모델링된 가새 골조의 구조상세모델과 구조 해석 소프트웨어의 연동을 통해 접합부설계에 필요한 Data를 공유하고 그 Data를 가지고 자동으로 브레이스 접합부설계가 수행될 수 있도 록 인터페이스 모듈을 개발하였다. 인터페이스 모듈을 통해 사용자가 필요한 구조해석결과정보를 쉽게 확인하 고 사용자가 편리하게 출력 및 저장할 수 있도록 하였다.

(3) 인터페이스 모듈의 개발을 통해 접합부의 구조설계를 위 해 반복되는 데이터 입력을 일괄적으로 처리함으로써 소 요시간, 입력정보의 에러를 감소시키며 이로 인해 업무 의 효율성과 생산성이 증가될 것으로 기대된다.

이상으로 브레이스 접합부 구조설계 인터페이스 모듈을 개 발하였으며, 향후 적용성과 사용성을 높이기 위해서, 적용성 면에서는 국내 건물의 가새골조에 사용되는 다양한 가새접합 부의 구조설계 분석이 요구되고, 사용성 면에서는 인터페이스 모듈이 사용자 입장에서 접근성이 쉽고 편리하게 구축될 필 요가 있을 것으로 사료된다.

\section{감사의 글}

이 논문은 2012년 정부(교육과학기술부)의 재원으로 한국 연구재단의 지원을 받아 수행된 연구임(2010-0003822).

\section{참 고 문 헌(References)}

〔1] 이강민(2007) KBC_S 2008(안)에서의 철골가새골조 내 진설계, 한국강구조학회학회지, 한국강구조학회, 제 19 권, 제4호, pp.25-38.

Lee, K.M. (2007) Seismic Provisions for Steel Braced Frames in the Draft of Korean Building Code Structures 2008, Magazine of Korean Society of Steel Construction, Vol. 19, No. 1, pp.25-38 (in Korean).

〔2] 최선규(2010) 강구조 가새 인장접합부 설계에 관한 고찰, 한국강구조학회학회지, 한국강구조학회, 제 22 권, 제 6 호, pp.9-13.
Choi, S.G. (2010) A Study on the Steel Bracing Connections for Tension, Magazine of Korean Society of Steel Construction, Vol. 22, No. 6, pp.9-13 (in Korean).

〔3] 이재철, 정종현, 김치경, 김지현, 김민수(2012), $\mathrm{IFC}$ 를 이용한 건축강구조 표준접합상세의 표현, 대한건축학회 논 문집, 대한건축학회, 제28권, 제7호, pp.65-72.

Lee, J., Jung, J., Kim, C., Kim, J., and Kim, M.S. (2012) Representation of Standard Steel Connections using IFC, Journal of Korean Society of Steel Construction, Vol. 28, No. 7, pp.65-72 (in Korean).

[4] 엄진업(2010) BIM기반의 구조상세설계 자동화 시스템 구축에 관한연구, 석사학위 논문, 동명대학교.

Eom, J.U. (2010) A Study on the Automation System of Structural Detail Design and Modeling Process based on BIM for Steel Structures, M.S. Dissertation, TongMyong University, Korea (in Korea).

[5] 엄진업, 신태송(2010) BIM기반의 철골접합부 모델링 자 동화에 관한 연구, 한국강구조학회논문집, 한국강구조학 회, 제22권, 제1호, pp.99-108.

Eom, J. and Shin, T.S. (2010) A Study on the Automation of the Connection Modeling for Steel Structures based on BIM, Journal of Korean Society of Steel Construction, KSSC, Vol. 22, No. 1, pp.99-108 (in Korean).

[6] Ram Connection Standalone 7.0, Bentley, 2010.

[7] 엄진업, 신태송(2011) BIM기반의 고력볼트 마찰접합부 설계자동화 시스템의 프로토타입 구축, 한국강구조학회 논문집, 한국강구조학회, 제23권, 제5호, pp.637-646.

Eom, J. and Shin, T.S. (2011) A Development of Prototype Design Automation System for Standard Connections Using High-Strength Bolts Based on BIM, Journal of Korean Society of Steel Construction, KSSC, Vol. 23, No. 5, pp.637-646 (in Korean).

[8] 엄진업, 신태송(2011) BIM 기반의 구조설계와 상세설계 인터페이스 모듈 개발, 한국강구조학회논문집, 한국강구조 학회 제23권, 제1호, pp.113-124.

Eom, J. and Shin, T.S. (2011) A Development of Interface Module between Structural Design and Detail Design based on BIM, Journal of Korean Society of Steel Construction, KSSC, Vol. 23, No. 1, pp.113-124 (in Korean).

[9] Tekla Structures 17.0, TEKLA, 2011.

〔10] 박상현(2003) 비주얼 C\# 2005 익스프레스로 배우는 C\# 2.0 프로그래밍, 대림출판사.

Park, S. H. (2003) C\# 2005 Study to express C\# 
2.0 Programming, Dae Lim Publisher (in Korean).

[11] MathCad 14.0 (2006) PTC.

[12] 김태형, 신태송(2012) 브레이스 접합부 형태에 따른 적 정성 비교, 2012년 한구강구조학회 학술대회발표집, 한 국강구조학회, pp.149-150.

Kim, T. and Shin, T.S. (2012) A Comparison with the Reasonableness according to Brace Types, Proceedings of Annual Conference Korean Society of Steel Construction, KSSC, pp.149-150 (in Korean).

〔13] 대한건축학회(2010) 건축구조기준 및 해설, 기문당. Architectural Institute of Korea (2010) Korean Building Code and Commentary, Kimoondang Publisher (in Korean).

〔14] 한국건축구조기술사회(2010) 강구조내진설계메뉴얼, 구미 서관.

The Korean Structural Engineers Association (2010)

Seismic Design Manual for Steel Structures (KSEA 732-10), Goomisugawn Publisher (in Korean).
[15] 한국강구조학회(2009) KBC2009 강구조 설계, 구미서관. KSSC (2009) KBC2009 Steel Sturctural Design, Goomisugwan Publisher (in Korean)

[16] AISC (2005) Specification for Structual Steel Buildings, ANSI/AISC 360-05.

〔17] 김태형, 신태송(2012) BIM 기반의 브레이스 접합부 설계 프로세스 및 프로토타입 구축, 대한건축학회 지회연 합 발표논문집, 대한건축학회, 제8권, 제1호, pp.87-88.

Kim, T. and Shin, T.S. (2012) An Implementation of the Structural Design Process and the Prototype for Brace Connections Based on BIM, Proceedings of Annual Conference Architectural Institute of Korea, Architectural Institute of Korea, Vol. 8, No. 1, pp.87-88 (in Korean).

〔18] Larry S.Mur (2008) Designing Compact Gussets with the Uniform Force Method, Engineering Journal. Vol. 45, No. 1, pp.13-19.

요 약 : 본 연구는 강구조물의 실시설계 단계에서 브레이스 접합부의 구조설계 및 BIM 모델링의 효율성을 제고하기 위한 것으로 브레 이스 접합부의 구조설계 인터페이스 모듈 개발을 목적으로 한다. 이를 위하여 국내·외의 구조설계기준을 분석하여 알고리즘을 작성하고 이를 바탕으로 구조설계모듈을 구축하였다. 또한 BIM 설계 도구와 연동하여 모델 데이터로부터 구조설계를 수행하기 위한 입·출력 데이터를 자 동으로 생성하며, 구조설계 결과로부터 BIM 모델을 자동으로 생성할 수 있는 인터페이스 모듈을 개발하였다. 예제 모델을 통해 개발된 모듈 의 효율성과 실용성을 검증하였다.

핵 심 용 어 : 실시설계, 브레이스 접합부, BIM, 인터페이스 모듈, 알고리즘 